\title{
Paradoxical reaction in tuberculous meningitis: presentation, predictors and impact on prognosis
}

Anurag Kumar Singh ${ }^{1 \dagger}$, Hardeep Singh Malhotra ${ }^{1 \dagger}$, Ravindra Kumar Garg ${ }^{1 * \dagger}$, Amita Jain ${ }^{2}$, Neeraj Kumar ${ }^{1}$, Neera Kohli ${ }^{3}$, Rajesh Verma ${ }^{1}$ and Praveen Kumar Sharma ${ }^{1}$

\begin{abstract}
Background: Awareness about paradoxical reactions in tuberculous meningitis is crucial as a paradoxical reaction may lead to certain wrong conclusions (for example, an erroneous diagnosis, and a possibility of treatment failure, mycobacterial drug-resistance, drug toxicity, or presence of a malignancy). The present study was planned to evaluate the incidence and predictive factors of paradoxical reactions in light of clinical, cerebrospinal fluid, and neuroimaging characteristics.
\end{abstract}

Methods: In this prospective cohort study, consecutive patients fulfilling the International Consensus criteria of tuberculous meningitis were included. Patients were subjected to clinical evaluation, cerebrospinal fluid evaluation, and neuroimaging. Patients were treated with anti-tuberculosis drugs along with corticosteroids. Patients were regularly followed up at 3 monthly intervals. At each follow up patients were evaluated clinically and repeat cerebrospinal fluid analysis was performed along with repeat neuroimaging. Disability assessment was done using Barthel index.

Results: We enrolled 141 patients of tuberculous meningitis. Approximately one-third of patients $(44 / 141 ; 31.2 \%)$ developed a paradoxical reaction. Twenty-seven patients developed hydrocephalus, 26 developed tuberculomas, 12 developed optochiasmatic arachnoiditis and 4 patients had spinal arachnoiditis. In 41 patients (out of 44) cerebrospinal fluid paradoxically worsened (increase in cells and/or protein); 2 demonstrated a decrease in cells with polymorph predominance while in one it was normal. In 3 patients, paradoxical cerebrospinal fluid changes were not associated with neuroimaging changes. On multivariate analysis, predictors of paradoxical reaction were female gender $(p=0.013)$, HIV positivity $(p=0.01)$ and a shorter duration of illness $(p=0.049)$. Development of paradoxical reactions did not predict the disability status of the patients.

Conclusions: Paradoxical reaction occurs in approximately one-third of patients with tuberculous meningitis. Female gender, concomitant HIV infection, and a shorter duration of illness were significant predictors. Paradoxical reactions did not adversely affect the outcome.

Keywords: Tuberculoma, Optochiasmatic arachnoiditis, Hydrocephalus, Cerebrospinal fluid, Immune reconstitution inflammatory syndrome

\footnotetext{
* Correspondence: garg50@yahoo.com

${ }^{\dagger}$ Equal contributors

1 Department of Neurology, King George Medical University, Uttar Pradesh,

Lucknow PIN-226003, India

Full list of author information is available at the end of the article
} 


\section{Background}

Paradoxical reaction, in patients with tuberculous meningitis, is characterized by either worsening of preexisting tuberculous lesions or the appearance of new tuberculous lesions in patients who show initial improvement following anti-tuberculosis treatment. The clinical or radiological deterioration associated with such a reaction may fallaciously suggest either a drug resistant state or treatment failure, and might even prompt to look for an alternative diagnosis [1-3]. The manifestations of paradoxical reaction, that have been described, are mostly derived from case reports and small case series. These include a variety of clinical manifestations and neuroimaging abnormalities, along with an altered cerebrospinal fluid picture. Cerebrospinal fluid changes may include lymphocytic pleocytosis, a change in cellular components in the direction of polymorphonuclear predominance, or an increase in protein levels. Paradoxical reaction does not necessarily represent treatment failure and corticosteroids have been shown to have a beneficial effect [4-6].

In human immunodeficiency virus (HIV)-infected patients, paradoxical reactions are termed as the immune reconstitution inflammatory syndrome (IRIS), which is a condition characterized with worsening of pre-existing infective processes, following treatment with antiretroviral therapy. Tuberculosis-associated immune reconstitution inflammatory syndrome is characterized by worsening of clinical symptoms, signs, and imaging characteristics of tuberculosis subsequent to initiation of antiretroviral therapy after initial improvement with anti-tuberculosis treatment $[7,8]$.

Most of the current information about paradoxical reaction in tuberculous meningitis is in the form of isolated case reports, small case series, and articles with small number of patients. The exact frequency and spectrum of paradoxical reaction is not precisely known. Its impact on prognosis is also not clear. This prospective follow up study has been planned to answer all these questions.

\section{Methods}

This prospective study was conducted in Department of Neurology, King George Medical University Uttar Pradesh, Lucknow. Our institute is a tertiary care hospital serving a population of approximately 100 million. It is situated in an area which is highly endemic for tuberculosis. Formal ethical approval was taken from the Institutional Ethics Committee, King George's Medical University, U.P., India. Written informed consent was obtained from all patients and/or their legal guardians.

\section{Inclusion criteria}

All consecutive newly-diagnosed patients of tuberculous meningitis, fulfilling the consensus diagnostic criteria as described by Marais et al., were included. Patients were categorized into definite, probable, or possible tuberculous meningitis groups on the basis of clinical, imaging, and laboratory criteria. The definite cases of tuberculous meningitis had either the presence of acid-fast bacilli in cerebrospinal fluid, or mycobacterium could be cultured from cerebrospinal fluid, or cerebrospinal fluid was positive for mycobacterial nucleic acids by polymerase chain reaction. The probable cases fulfilled the clinical entry criteria plus a total diagnostic score of 10 or more points (when cerebral imaging was not available) or 12 or more points (when cerebral imaging was available) plus exclusion of alternative diagnoses. The possible cases included clinical entry criteria plus a total diagnostic score of 6-9 points (when cerebral imaging was not available) or 6-11 points (when cerebral imaging was available) along with the exclusion of alternative diagnoses [9].

\section{Disease severity}

Patients were classified as per British Medical Research Council staging system. Patients with stage-I disease had a Glasgow Coma Scale score of 15 with no focal neurologic signs; patients with stage-II had signs of meningeal irritation with slight or no alteration of sensorium and minor neurological deficit (like cranial nerve palsies) or no deficit (Glasgow coma scale score 11 to14), and patients with stage-III had severe alteration of sensorium, convulsions, focal neurological deficit and involuntary movements (Glasgow coma scale score <10) [10].

\section{Evaluation of patients}

All enrolled patients were subjected to detailed clinical, radiological, and laboratory evaluation. Occurrence of systemic tuberculosis, such as involvement of pulmonary system, lymph node, bone, and other organs, were recorded. The work up included complete blood count, peripheral blood smear examination, erythrocyte sedimentation rate, blood urea nitrogen, blood sugar, serum creatinine, serum electrolytes, liver function tests, chest X-ray, and enzyme linked immunosorbent assay for HIV. Cerebrospinal fluid biochemical and microscopic examination, including India ink preparation, were performed. Cerebrospinal fluid sediments were stained, cultured (Lowenstein Jensen media), and tested for drug susceptibility by standard methods. Cerebrospinal fluid specimens were also tested for mycobacterial nucleic acids by polymerase chain reaction. Appropriate patients were also evaluated by performing bacterial screen with culture, cryptococcal latex antigen detection, antinuclear antibody, antineutrophil cytoplasmic antibody screen, hepatitis $\mathrm{B}$ and $\mathrm{C}$, and angiotensin converting enzyme level. Patients were subjected to MR imaging of the brain and/or spinal cord using Signa Excite 1.5 Tesla 
instrument (General Electric Medical Systems, Milwaukee, WI, USA.

\section{Exclusion criteria}

Patients with cryptococcal meningitis or any other cause for meningitis were excluded from the study.

\section{Definition of paradoxical reaction}

A paradoxical reaction was defined as the worsening of pre-existing tuberculous lesions or the appearance of new tuberculous lesions in patients whose clinical symptoms initially improved and had been on antituberculosis treatment for at least 10 days $[2,3,11]$. For the purpose of the calculation of "time of onset of paradoxical reaction" in the study participants only clinical deteriorations were considered from the time of initiation of anti-tuberculosis treatment; nonsymptomatic radiological worsening was defined either at the time of clinical deteriorations or at the predefined follow-up visit.

\section{Definition of other neuroimaging findings}

Hydrocephalus was defined as ventriculomegaly with Evan's ratio (maximal width of frontal horns/maximal width of inner skull) of more than $30 \%$ and/or size of one or both temporal horns greater than $2 \mathrm{~mm}$. Communicating hydrocephalus was characterized with ventriculomegaly with a dilated fourth ventricle. Meningeal inflammation, on gadolinium-enhanced MRI, was defined as an enhancement of pia-arachnoid mater covering subarachnoid spaces of the sulci and basal cisterns. Exudates were defined as a thick area of enhancement, predominantly in basal cisterns and Sylvian fissure. Optochiasmatic tuberculoma and arachnoiditis were characterized with confluent enhancing lesions involving interpeduncular fossa, pontine cistern, and perimesencephalic and suprasellar cisterns. Spinal arachnoiditis was defined with the presence of enhancement of spinal meninges, and nerve roots, obliteration of the spinal subarachnoid space, cysts and loculations in subarachnoid space, or syrinx formation. Tuberculomas were defined as discrete or coalescing cerebral masses showing nodular or ring shaped enhancement. Infarcts were areas of abnormal signal intensity in a vascular distribution, predominantly in periventricular region. Infarcts appeared hyperintense on T2-weighted images and hypointense on T1-weighted images, with corroborating changes on diffusion-weighted and apparent diffusion coefficient images.

\section{Treatment}

All included patients received anti-tuberculosis treatment as per World Health Organization guidelines for the treatment of central nervous system tuberculosis.
Patients received 2 months of daily oral isoniazid ( $5 \mathrm{mg} / \mathrm{kg}$ of body weight; maximum, $300 \mathrm{mg}$ ), rifampicin $(10 \mathrm{mg} / \mathrm{kg}$; maximum, $600 \mathrm{mg})$, pyrazinamide (25 mg/kg; maximum, $2 \mathrm{~g} /$ day) and intramuscular streptomycin $(20 \mathrm{mg} / \mathrm{kg} ;$ maximum $1 \mathrm{gm} /$ day $)$, followed by at least 7 months administration of isoniazid and rifampicin [12]. Corticosteroid regimen consisted of intravenous dexamethasone for 4 weeks $(0.4 \mathrm{mg} / \mathrm{kg}$ body weight per day and then tapered off decreasing $0.1 \mathrm{mg} / \mathrm{kg}$ every week) and then oral treatment for 4 weeks, starting at a total of $4 \mathrm{mg}$ per day and decreasing by $1 \mathrm{mg}$ each week [13]. Pyridoxine was given orally $20-40 \mathrm{mg} /$ day to all the patients. In addition, patients received symptomatic treatment as well. Neurosurgical opinion was sought, whenever required.

In HIV-infected patients antiretroviral therapy was administered under supervision of the Nodal antiretroviral therapy unit. Antiretroviral therapy was started as soon as anti-tuberculosis treatment was tolerated (between 2 weeks and 2 months), as per National AIDS Control Organization, Government of India, guidelines [14].

\section{Disability assessment}

Disability assessment was done using Barthel index (BI), which is a 20 point scoring system. Assessment of disability included degree of dependence for bowel and bladder, grooming, toilet use, transfer, mobility, dressing, feeding, use of stairs and bathing. For each activity, a score of 0 indicated a complete dependence, and an individual score of 2 or 3 indicated that the patient was able to perform activities independently. A score of $\leq 12$ indicated poor functional status and a score of $>12$ indicated good functional status.

\section{Follow up}

Patients were regularly followed up for 9 months. Besides a defined follow up at 3, 6, and 9 months, clinical assessment and cerebrospinal fluid analysis were also done at the time of clinical deterioration. Changes in cerebrospinal fluid parameters (like cells, protein and sugar) were noted. Polymorphonuclear predominance was defined when these constituted $>50 \%$ of cells. Repeat neuroimaging were performed after 3 months and 6 months, or at periods of clinical deteriorations. Neuroimaging were looked for any deterioration or new findings. Assessment of disability was done at the end 9 months of follow up. Barthel index $>12$ was considered as good outcome. Intervening visits mandated by clinical deteriorations generated off-pre-defined visit data which was additionally recorded. 


\section{Statistical analysis}

Statistical analysis was performed using the Statistical Package for Social Sciences, version 16 for windows (SPSS, Chicago IL, USA). Both univariate and multivariate analysis were done to evaluate the predictors of paradoxical reaction. Univariate analysis was performed by Chi-square test for categorical variables and independent sample " $t$ " test for continuous variables. Odds ratio with $95 \%$ confidence interval were ascertained. For multivariate analysis, binary logistic regression was performed to see the impact of individual predictors of paradoxical reaction. Paired sample "t" test and McNemar tests were used to compare quantitative and qualitative variables before and during development of paradoxical reaction. Kaplan Meier analysis was performed to estimate the event free survival for the outcome with or without baseline paradoxical reaction using the Log Rank test. Statistical significance was defined at a $\mathrm{p}$ value of $<0.05$. All statistical analyses were two-tailed.

\section{Results}

\section{Baseline characteristics}

We screened 156 consecutive patients of tuberculous meningitis during the study period which ranged from October 2013 to March 2015. Fifteen patients were excluded. Reasons for exclusion of 15 patients have been provided in Fig. 1. Finally, 141 patients were included and evaluated. Majority of our patients 66 (46.8\%), at inclusion, were in stage-II. Thirteen patients were HIV positive. There were 54 (38.3 \%) microbiologicallyconfirmed cases. One patient had multidrug resistant tuberculous meningitis and was included in the nonparadoxical reaction group. In the paradoxical reaction group the mean duration of illness was $42.93 \pm 21.58$ (median $=38$, range 18-107) days while in the non-paradoxical reaction group the mean duration of illness was $52.49 \pm$ $27.54($ median $=45$, range $5-180)$ days $($ Table 1$)$.

\section{Incidence of paradoxical reaction}

In our study, 44 (31.2 \%) patients developed some form of paradoxical reaction. In majority (29 patients), paradoxical reactions were noted within 3 months of start of anti-tuberculosis treatment. Mean duration of paradoxical reaction was 82.45 days (16-320 days) (Additional file file 1: Table S1).

\section{Manifestations of paradoxical reaction}

Fever, headache, altered sensorium, decreased vision, and seizures were common clinical paradoxical reactions among 44 patients who presented with a paradoxical reaction. Among neuroimaging changes, enhancing basal exudates, a new or enlargement of pre-existing tuberculoma, development of infarcts, and increasing ventriculomegaly were the more frequent paradoxical reactions. Twenty-six (59\%) patients developed either a new (15 patients) or enlargement (11 patients) of pre-existing tuberculoma. Twenty patients demonstrated newly developed hydrocephalus while in 7 cases ventricular size had increased further. Optochiasmatic arachnoiditis was the other common but disabling paradoxical manifestation. Four patients, additionally, had spinal arachnoiditis. In 41 patients, cerebrospinal fluid paradoxically

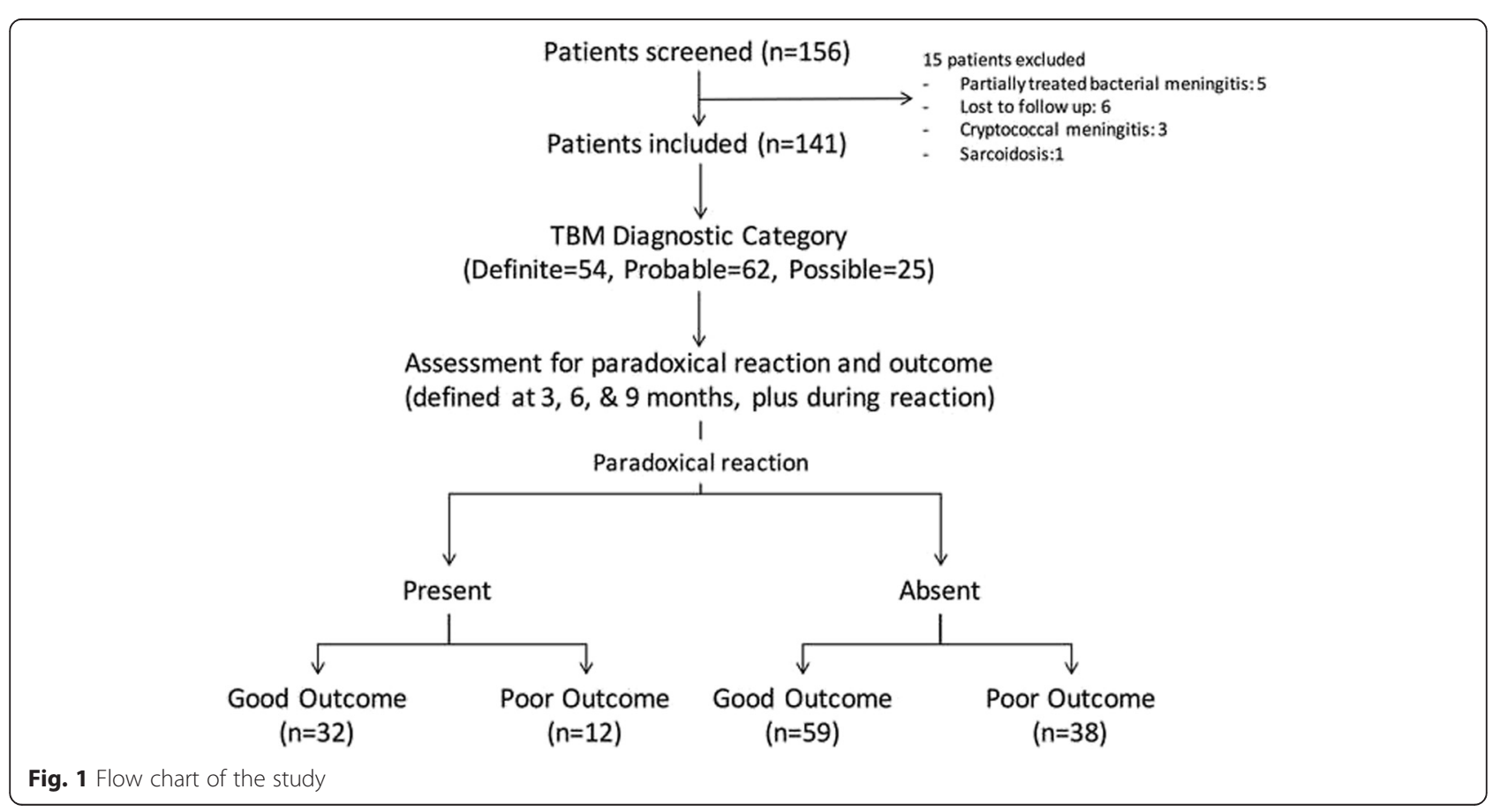


Table 1 Baseline characteristics, radiological and cerebrospinal fluid parameters, and outcome of patients with tuberculous meningitis

\begin{tabular}{|c|c|c|c|}
\hline & $\begin{array}{l}\text { Total numbers of patients included } \\
(n=141)\end{array}$ & $\begin{array}{l}\text { Paradoxical manifestation } \\
(n=44)\end{array}$ & $\begin{array}{l}\text { No paradoxical manifestation } \\
(n=97)\end{array}$ \\
\hline \multicolumn{4}{|l|}{ Demographic } \\
\hline Age (Mean \pm SD) & $29.75 \pm 12.79$ & $27.295 \pm 10.95$ & $30.866 \pm 13.44$ \\
\hline Duration of illness (Mean \pm SD) & $49.51 \pm 26.13$ & $42.932 \pm 21.58$ & $52.495 \pm 27.53$ \\
\hline \multicolumn{4}{|l|}{ Gender (n, \%) } \\
\hline Male & $76(53.9 \%)$ & $18(40.9 \%)$ & $58(59.8 \%)$ \\
\hline Female & $65(46.1 \%)$ & $26(59.1 \%)$ & $39(40.2)$ \\
\hline HIV $(n, \%)$ & 13(9.2\%) & $11(25 \%)$ & $2(2.1 \%)$ \\
\hline \multicolumn{4}{|l|}{ Clinical (n, \%) } \\
\hline BMRC stage 1 & $31(22.0 \%)$ & $8(18.2 \%)$ & $23(23.7 \%)$ \\
\hline BMRC stage 2 & $66(46.8 \%)$ & $21(47.7 \%$ & $45(46.4 \%)$ \\
\hline BMRC stage 3 & $44(31.2 \%)$ & 15(34.1\%) & $29(29.9 \%)$ \\
\hline Fever & 138(97.8 \%) & $43(97.7 \%)$ & $95(97.9 \%)$ \\
\hline Headache & $131(92.90 \%)$ & $39(88.6 \%)$ & $92(94.8 \%)$ \\
\hline Seizure & $48(34.0 \%)$ & $12(27.3 \%)$ & $36(37.1 \%)$ \\
\hline Altered Sensorium & $44(31.2 \%)$ & $15(34.1 \%)$ & $29(29.9 \%)$ \\
\hline Decreased vision & $35(24.8 \%)$ & $10(22.7 \%)$ & $25(25.8 \%)$ \\
\hline Hemiparesis & $23(16.3 \%)$ & 7(15.9\%) & $16(16.5 \%)$ \\
\hline Paraparesis & $12(8.5 \%)$ & $2(4.5 \%)$ & 10(10.3\%) \\
\hline Meningeal signs & 125(88.7 \%) & $41(93.2 \%)$ & $84(86.6 \%)$ \\
\hline Lymphadenopathy & $13(9.2 \%)$ & $10(22.7 \%)$ & 3(3.1\%) \\
\hline Diplopia & $59(41.8 \%)$ & $17(38.6 \%)$ & $42(43.3 \%)$ \\
\hline Cranial Nerve involvement & $80(56.7 \%)$ & $27(61.4 \%)$ & $53(54.6 \%)$ \\
\hline Papilloedema & $50(62.5 \%)$ & $13(29.5 \%)$ & $42(43.3 \%)$ \\
\hline \multicolumn{4}{|l|}{ Imaging (n, \%) } \\
\hline Hydrocephalus & $53(37.6 \%)$ & $13(29.5 \%)$ & $40(41.2 \%)$ \\
\hline Basal Exudates & $38(27.0 \%)$ & $9(20.5 \%)$ & $29(29.9 \%)$ \\
\hline Tuberculoma & $51(36.2 \%)$ & $15(34.1 \%)$ & $36(37.1 \%)$ \\
\hline Infarct & $25(17.7 \%)$ & 7(15.9\%) & $18(18.6 \%)$ \\
\hline Optochiasmatic arachnoiditis & $21(14.9 \%)$ & $7(15.9 \%)$ & $14(14.4 \%)$ \\
\hline Spinal arachnoiditis & $12(8.5 \%)$ & $2(4.5 \%)$ & 10(10.3\%) \\
\hline \multicolumn{4}{|l|}{ Cerebrospinal fluid } \\
\hline White blood cells (cells/mL \pm SD) & $189.610 \pm 185.66$ & $200.864 \pm 121.26$ & $184.505 \pm 208.809$ \\
\hline Protein mg\% & $253.704 \pm 455.84$ & $188.5382 \pm 115.145$ & $283.2649 \pm 542.511$ \\
\hline Sugar mg\% & $35.311 \pm 18.46$ & $33.620 \pm 18.231$ & $36.086 \pm 18.61$ \\
\hline $\begin{array}{l}\text { Neutrophil differential in percentage, } \\
\text { mean } \pm S D\end{array}$ & $17.21 \pm 19.250$ & $19.705 \pm 21.368$ & $16.072 \pm 18.210$ \\
\hline $\begin{array}{l}\text { Lymphocyte differential in percentage } \\
\text { (mean } \pm \text { SD) }\end{array}$ & $83.65 \pm 18.02$ & $80.295 \pm 21.368$ & $85.175 \pm 16.166$ \\
\hline AFB smear $(n, \%)$ & $4(2.8 \%)$ & $1(2.27 \%)$ & $3(3.09 \%)$ \\
\hline AFB culture positive $(n, \%)$ & $21(14.9 \%)$ & $11(25 \%)$ & $10(10.30 \%)$ \\
\hline TB PCR-positive (n, \%) & $50(35.5 \%)$ & $22(50 \%)$ & $28(28.86 \%)$ \\
\hline
\end{tabular}


Table 1 Baseline characteristics, radiological and cerebrospinal fluid parameters, and outcome of patients with tuberculous meningitis (Continued)

\begin{tabular}{|c|c|c|c|}
\hline \multicolumn{4}{|c|}{ Diagnostic category $(\mathrm{n}, \%)$} \\
\hline Definite & $54(38.3 \%)$ & $20(45.5 \%)$ & $34(35.1 \%)$ \\
\hline Probable & $62(44.0 \%)$ & $19(43.2 \%)$ & $43(44.3 \%)$ \\
\hline Possible & $25(17.7 \%)$ & $5(11.4 \%)$ & $20(20.6 \%$ \\
\hline \multicolumn{4}{|l|}{ Disability (n, \%) } \\
\hline Baseline $\mathrm{BI}(<12)$ & $93(66.0 \%)$ & $34(77.3 \%)$ & $59(60.8 \%)$ \\
\hline Baseline $\mathrm{BI}(>12)$ & $48(34.0 \%)$ & $10(22.7 \%)$ & $38(39.2 \%)$ \\
\hline \multicolumn{4}{|l|}{ Outcome (n, \%) } \\
\hline Poor $(B \mid<12)$ & $50(35.5 \%)$ & $12(27.3 \%)$ & $38(39.2 \%)$ \\
\hline Good (Bl>12) & $91(64.5 \%)$ & $32(72.7 \%)$ & $59(60.8 \%)$ \\
\hline
\end{tabular}

AFB acid fast bacilli, BMRC British Medical Research Council, HIV human immunodeficiency virus, BI Barthel index, TB PCR tuberculosis polymerase chain reaction

worsened (increase in cells with or without rise in protein level). Out of the remaining 3 , two patients demonstrated a decrease in the cell count but with polymorph predominance (not present at the baseline) while in one the cerebrospinal fluid was normal. In cerebrospinal fluid, major changes observed were increase in protein level and increase in polymorphs. In 3 patients with paradoxical reaction, only cerebrospinal fluid changes (without imaging changes) were noted. Fourteen patients had paradoxical lymphadenopathy while three patients had developed miliary tuberculosis (Fig. 2) (Additional file 1: Table S1). Statistically significant changes from the baseline to the time of development of paradoxical reaction was observed in fever, headache, hydrocephalus, tuberculoma, c-reactive protein, erythrocyte sedimentation rate, and cerebrospinal fluid polymorphs, lymphocytes, and protein (Table 2).

\section{Predictors of paradoxical reaction}

On univariate analysis, female gender $(p=0.037)$, HIV positivity $(p=<0.001)$, lymphadenopathy $(p=0.001)$ and a shorter duration of illness $(p=0.028)$ were significantly associated with development of paradoxical reaction (Table 3). On multivariate analysis, female gender $(p=0.013$, OR $=2.87$, CI 1.24-6.62), HIV positivity $(p=0.010$, OR = 31.49; $\mathrm{CI}=2.31-426.21)$, and a shorter duration of illness $\quad(p=0.049, \quad \mathrm{OR}=0.98 \quad \mathrm{CI}=.963-1.00) \quad$ were found to be statistically significant predictors of paradoxical reaction (Table 4).

\section{Impact on prognosis}

Overall, duration of illness, alteration in consciousness, stage-III of tuberculous meningitis, and hydrocephalus predicted poor prognosis among patients with tuberculous meningitis. In the paradoxical group $24 \%$ patients had poor outcome compared to $35.2 \%$ with good outcome, which was statistically not significant (Table 5). We did not observe any significant difference in the proportion of patients having poor disability status after end of follow up. Kaplan-Meier survival statistics did not demonstrate any significant difference in survival between both groups (Fig. 3).

\section{Discussion}

In this prospective study approximately one-third of patients with tuberculous meningitis developed paradoxical

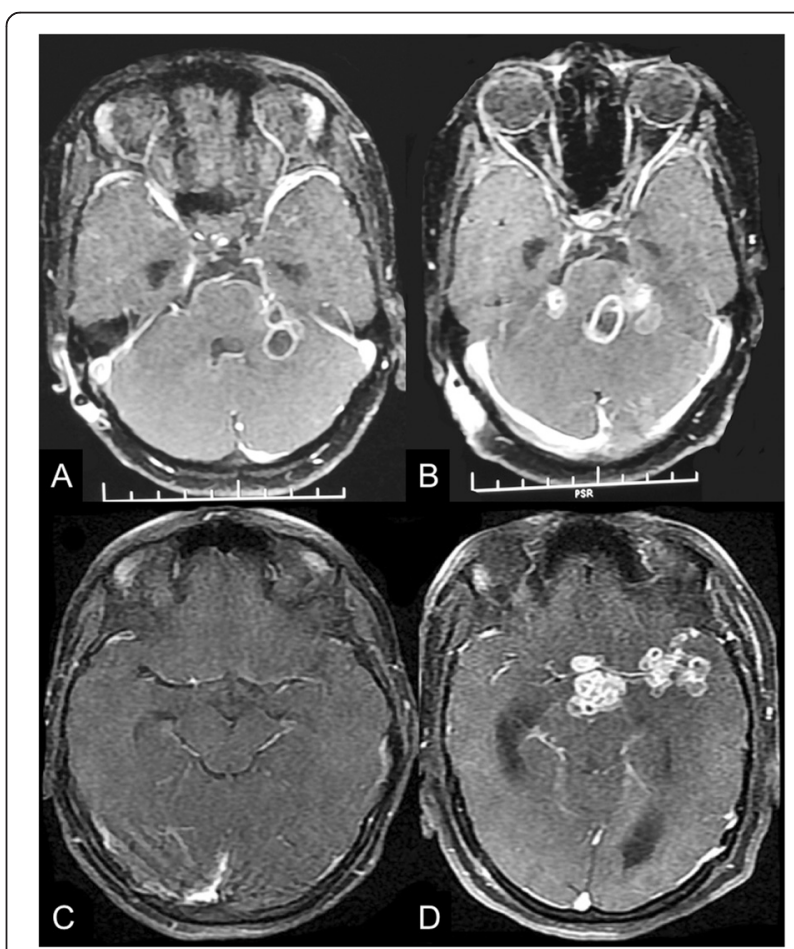

Fig. 2 T1-weighted Gadolinium-enhanced MRI (axial sections) of the brain of a patient with TBM depict the development of additional (paradoxical) tuberculoma (Baseline-a, at 5th month-b) at the pontocerebellar level. Similar sequence in another patient shows development of paradoxical optochiasmatic arachnoiditis along with multiple tuberculomas (Baseline-c, at 3rd month-d) 
Table 2 Comparative analysis of variables of patients with paradoxical reaction

\begin{tabular}{|c|c|c|c|}
\hline Variable & At baseline & During pxaradoxical reaction & $P$ value \\
\hline Fever & 43 & 29 & .001 \\
\hline Headache & 39 & 27 & .008 \\
\hline Seizure & 12 & 11 & 1.0 \\
\hline Altered Sensorium & 15 & 12 & .664 \\
\hline Decreased vision & 10 & 16 & .180 \\
\hline Hemiparesis & 7 & 9 & .791 \\
\hline Paraparesis & 2 & 4 & .688 \\
\hline Hydrocephalus & 13 & 27 & .009 \\
\hline Tuberculoma & 15 & 26 & .019 \\
\hline Basal Exudate & 9 & 12 & .648 \\
\hline Optochiasmatic arachnoiditis & 7 & 12 & .332 \\
\hline Infarct & 7 & 9 & .791 \\
\hline Spinal arachnoiditis & 2 & 4 & .688 \\
\hline CRP & 19 & 28 & .004 \\
\hline ESR & $27.818 \pm 4.876$ & $33.20 \pm 5.889$ & .027 \\
\hline CSF cells & $200.864 \pm 121.260$ & $210.295 \pm 125.761$ & .058 \\
\hline CSF Polymorph & $19.705 \pm 21.368$ & $37.84 \pm 23.716$ & .008 \\
\hline CSF Lymphocytes & $80.295 \pm 21.368$ & $62.39 \pm 23.398$ & .012 \\
\hline CSF Protein & $188.538 \pm 115.145$ & $261.355 \pm 152.0650$ & $<.001$ \\
\hline CSF sugar & $33.620 \pm 43.2566$ & $43.256 \pm 17.998$ & .261 \\
\hline
\end{tabular}

CRP C-reactive protein, CSF cerebrospinal fluid, ESR Erythrocyte sedimentation rate Note: Statistically significant $P$-values are depicted in italics

changes. In almost all patients, clinical/imaging paradoxical manifestations accompanied paradoxical cerebrospinal fluid changes. We encountered a variety of manifestations of paradoxical reactions. These paradoxical clinical and neuroimaging manifestations were either aggravated or appeared for the first time during illness, despite of an adequate anti-tuberculosis treatment. Expansion of existing cerebral tuberculomas and appearance of new tuberculomas, hydrocephalus, and optochiasmatic and spinal arachnoiditis, were common paradoxical manifestations.

Paradoxical reactions in these patients result because of an excessive inflammatory response against mycobacterial antigens. Mycobacterial cell wall antigens are present in the affected brain tissues and trigger an exaggerated inflammatory reaction following treatment with anti-tuberculosis drugs. Cheng and colleagues had noted a surge in blood lymphocyte counts accompanied by an increased tuberculin skin reaction during paradoxical response indicating that this immune response is similar to immune restoration syndrome seen in HIV-infected patients. Possibly, due to a paradoxical shift in the cellular components of the cerebrospinal fluid (from lymphocytic predominance to polymorph predominance), neutrophils also play a role in the pathogenesis of paradoxical reaction in patients with tuberculous meningitis.
[15] Sütlaş and co-workers followed 61 patients with confirmed or presumed tuberculous meningitis. Patients were categorized into two groups according to the presence of paradoxical response (progressive increase of lymphocytes or increase of polymorphonuclear cells instead of lymphocytes) in cerebrospinal fluid samples. Paradoxical response in the cerebrospinal fluid was seen in 20 patients. New tuberculomas developed more frequently in the group having paradoxical cerebrospinal fluid response. We had similar observations in our study where 41 patients with clinical/imaging paradoxical changes had paradoxical cerebrospinal fluid changes. Interestingly, in two patients where the cells actually decreased, there was a shift towards polymorph predominance. It has been observed that paradoxical cerebrospinal fluid changes occur after several weeks of starting anti-tuberculosis treatment and may not be associated with any clinical or neuroimaging deterioration [16].

We observed that female gender, concomitant HIV infection, and a shorter duration of illness, were significant predictors of paradoxical reactions in patients with tuberculous meningitis. Females exhibit more-robust immune responses to antigenic challenges, like infection and vaccination, in comparison to that in males. Given the fact that immune cells express specific receptors for 
Table 3 Predictors of paradoxical reaction on univariate analysis

\begin{tabular}{|c|c|c|c|c|c|c|}
\hline \multirow[t]{2}{*}{ Characteristic } & \multicolumn{2}{|l|}{ Paradoxical reaction } & \multirow[t]{2}{*}{$P$ value } & \multirow{2}{*}{$\begin{array}{l}\text { Odds } \\
\text { ratio }\end{array}$} & \multicolumn{2}{|c|}{$95 \%$ Confidence interval } \\
\hline & Present $(n=44)$ & Absent $(n=97)$ & & & Lower bound & Upper bound \\
\hline Age in years Mean $\pm S D$ & $27.295 \pm 10.958$ & $30.866 \pm 13.446$ & 0.125 & & -1.004 & 8.145 \\
\hline Duration of illness (days) Mean \pm SD & $42.932 \pm 21.583$ & $52.495 \pm 27.538$ & 0.028 & & 0.276 & 18.850 \\
\hline Gender (female) & 26 (59.1\%) & $39(40.2 \%)$ & 0.037 & 2.148 & 1.04 & 4.436 \\
\hline HIV positive & $11(25 \%)$ & $2(2.1 \%)$ & $<0.001$ & 15.833 & 3.334 & 75.184 \\
\hline Fever & $43(97.7 \%)$ & 95(97.9 \%) & 0.936 & 0.905 & 0.080 & 10.255 \\
\hline Headache & 39(88.6 \%) & $92(94.8 \%)$ & 0.183 & 0.424 & 0.116 & 1.548 \\
\hline Seizure & $12(27.3 \%)$ & $36(37.1 \%)$ & 0.253 & 0.635 & 0.291 & 1.387 \\
\hline Altered Sensorium & 15(34.1\%) & $29(29.9 \%)$ & 0.618 & 1.213 & 0.567 & 2.593 \\
\hline Decreased vision & $10(22.7 \%)$ & $25(25.8 \%)$ & 0.698 & 0.847 & 0.366 & 1.960 \\
\hline Hemiparesis & $7(15.9 \%)$ & $16(16.5 \%)$ & 0.930 & 0.958 & 0.363 & 2.526 \\
\hline Paraparesis & $2(4.5 \%)$ & $10(10.3 \%)$ & 0.341 & 0.414 & 0.087 & 1.976 \\
\hline Meningeal signs & $41(93.2 \%)$ & 84(86.6 \%) & 0.253 & 2.115 & 0.571 & 7.837 \\
\hline Lymphadenopathy & $10(22.7 \%)$ & 3(3.1 \%) & 0.001 & 9.216 & 2.393 & 35.496 \\
\hline Diplopia & $17(38.6 \%)$ & $42(43.3 \%)$ & 0.603 & 0.825 & 0.398 & 1.707 \\
\hline Cranial Nerve involvement & $27(61.4 \%)$ & $53(54.6 \%)$ & 0.455 & 1.319 & 0.638 & 2.727 \\
\hline Papilloedema & $13(29.5 \%)$ & $42(43.3 \%)$ & 0.121 & 0.549 & 0.256 & 1.177 \\
\hline Hydrocephalus & $13(29.5 \%)$ & $40(41.2 \%)$ & 0.184 & 0.598 & 0.279 & 1.282 \\
\hline Basal Exudates & $9(20.5 \%)$ & $29(29.9 \%)$ & 0.242 & 0.603 & 0.257 & 1.413 \\
\hline Tuberculoma & $15(34.1 \%)$ & $36(37.1 \%)$ & 0.729 & 0.876 & 0.415 & 1.850 \\
\hline Infarct & 7(15.9\%) & $18(18.6 \%)$ & 0.703 & 0.830 & 0.319 & 2.161 \\
\hline Optochiasmatic Arachnoiditis & $7(15.9 \%)$ & $14(14.4 \%)$ & 0.820 & 1.122 & 0.418 & 3.008 \\
\hline Spinal cord & $2(4.5 \%)$ & $10(10.3 \%)$ & 0.256 & 0.414 & 0.087 & 1.976 \\
\hline CRP & 19(43.2 \%) & $38(39.2 \%)$ & 0.653 & 1.180 & 0.573 & 2.430 \\
\hline Stage 3 TBM & $15(34.1 \%)$ & $29(29.9 \%)$ & 0.618 & 1.213 & 0.567 & 2.593 \\
\hline Baseline BI $(<12)$ & $34(77.3 \%)$ & $59(60.8 \%)$ & 0.056 & 2.190 & 0.970 & 4.944 \\
\hline Definite TBM & $20(45.5 \%)$ & $34(35.1 \%)$ & 0.312 & 1.544 & .748 & 3.189 \\
\hline Good outcome (Bl>12) & $32(72.7 \%)$ & $59(64.8 \%)$ & 0.171 & 0.582 & 0.267 & 1.268 \\
\hline ESR $\mathrm{mm}$ in $1 \mathrm{~h}$ Mean $\pm \mathrm{SD}$ & $27.818 \pm 4.876$ & $27.093 \pm 7.593$ & 0.497 & & -3.194 & 1.743 \\
\hline CSF Cells/ $\mu \mathrm{L}$ Mean \pm SD & $200.864 \pm 121.261$ & $184.505 \pm 208.810$ & 0.630 & & 83.265 & 56.548 \\
\hline CSF protein $(\mathrm{mg} / \mathrm{dl})$ Mean \pm SD & $188.5382 \pm 115.145$ & $283.2649 \pm 542.511$ & 0.254 & & -68.924 & 258.377 \\
\hline CSF sugar $(\mathrm{mg} / \mathrm{dl})$ Mean $\pm \mathrm{SD}$ & $33.620 \pm 18.231$ & $36.086 \pm 18.617$ & 0.465 & & 4.193 & 9.125 \\
\hline
\end{tabular}

BI Barthel Index, CRP C-reactive protein, CSF cerebrospinal fluid, ESR Erythrocyte sedimentation rate, HIV Human Immunodeficiency Virus, TBM Tuberculous meningitis

Note: Statistically significant $P$-values are depicted in italics

Table 4 Predictors of paradoxical reaction on multivariate analysis

\begin{tabular}{lllll}
\hline Characteristic & $P$ value & $\begin{array}{l}\text { Odds } \\
\text { ratio }\end{array}$ & & \multicolumn{2}{l}{$95 \%$ Confidence interval } \\
\cline { 5 - 6 } & & & Lower bound & Upper bound \\
\hline Duration & .049 & .981 & 0.963 & 1.000 \\
Gender (female) & .013 & 2.873 & 1.246 & 6.626 \\
HIV & .010 & 31.407 & 2.314 & 426.215 \\
Lymphadenopathy & .813 & 0.746 & 0.066 & 8.465 \\
\hline
\end{tabular}

HIV human immunodeficiency virus

Note: Statistically significant $P$-values are depicted in italics sex hormones and are responsive to changes in hormone levels, this gender variation might be explained by the modulatory effect of female sex hormones on the immune response towards Mycobacterium tuberculosis associated antigens $[17,18]$.

Patients with disseminated or extrapulmonary disease are considered to have higher bacillary/antigen loads, with a relative immunodeficient response, resulting in an increased risk of both paradoxical reactions and IRIS. Use of bactericidal drugs, such as isoniazid, may cause a massive release of bacterial components and provoke 
Table 5 Predictors of disability and outcome on univariate analysis in patients with tuberculous meningitis

\begin{tabular}{|c|c|c|c|c|c|c|}
\hline \multirow[t]{2}{*}{ Characteristics } & \multirow[t]{2}{*}{$\mathrm{BI} \leq 12(n=50)$} & \multirow[t]{2}{*}{$\mathrm{Bl}>12(n=91)$} & \multirow[t]{2}{*}{$P$ value } & \multirow{2}{*}{$\begin{array}{l}\text { Odds } \\
\text { Ratio }\end{array}$} & \multicolumn{2}{|c|}{$95 \%$ Confidence interval } \\
\hline & & & & & Lower bound & Upper bound \\
\hline Age & $29.320 \pm 11.881$ & $29.989 \pm 13.322$ & .768 & & -3.797 & 5.135 \\
\hline Duration of illness & $42.140 \pm 21.204$ & $53.560 \pm 27.761$ & .013 & & 2.495 & 20.345 \\
\hline Gender & $22(44 \%)$ & $54(59.3 \%)$ & .080 & .538 & .268 & 1.082 \\
\hline \multicolumn{7}{|l|}{ HIV } \\
\hline Fever & 49(98\%) & $89(97.8 \%)$ & .938 & 1.101 & .097 & 12.453 \\
\hline Headache & 44(88 \%) & $87(95.6 \%)$ & .092 & .337 & .090 & 1.257 \\
\hline Seizure & 15(30.0\%) & 33(36.3 \%) & .453 & .753 & .359 & 1.580 \\
\hline Altered Sensorium & $31(62.0 \%)$ & 13(14.3\%) & $<.001$ & 9.789 & 4.316 & 22.206 \\
\hline Decreased vision & 16(32.0\%) & $19(20.9 \%)$ & .144 & 1.783 & .817 & 3.891 \\
\hline Hemiparesis & $9(18.0 \%)$ & 14(15.4\%) & .688 & 1.207 & .482 & 3.027 \\
\hline Paraparesis & $6(12.0 \%)$ & $6(6.6 \%)$ & .271 & 1.932 & .588 & 6.342 \\
\hline Meningeal signs & $44(88.0 \%)$ & $81(89 \%)$ & .856 & .905 & .308 & 2.657 \\
\hline Lymphadenopathy & $4(8.0 \%)$ & $9(9.9 \%)$ & .711 & .792 & .231 & 2.716 \\
\hline Diplopia & 19(38.0\%) & $40(44.0 \%)$ & .493 & .821 & .402 & 1.675 \\
\hline Cranial Nerve involvement & $28(56.0 \%)$ & $52(57.1 \%)$ & .896 & .955 & .476 & 1.914 \\
\hline Papilloedema & 18(36.0 \%) & $37(40.7 \%)$ & .587 & .821 & .402 & 1.675 \\
\hline Hydrocephalus & $40(80.0 \%)$ & $13(14.3 \%)$ & $<.001$ & 24.0 & 9.677 & 59.520 \\
\hline Basal Exudates & $12(24.0 \%)$ & $26(28.6 \%)$ & .558 & .789 & .357 & 1.744 \\
\hline Tuberculoma & $22(44.0 \%)$ & 29(31.9\%) & .151 & 1.680 & .825 & 3.422 \\
\hline Infarct & $9(18.0 \%)$ & 16(17.6\%) & .950 & 1.029 & .418 & 2.533 \\
\hline Optochiasmatic arachnoiditis & 7(14.0 \%) & 14(15.4\%) & .825 & .895 & .336 & 2.388 \\
\hline Spinal arachnoiditis & $6(12.0 \%)$ & $6(6.6 \%)$ & .271 & 1.932 & .588 & 6.342 \\
\hline Stage-III TBM & $31(62.0 \%)$ & $13(14.3 \%$ & $<.001$ & 9.789 & 4.316 & 22.206 \\
\hline Definite TBM & $23(46.0 \%)$ & $31(34.1 \%)$ & .163 & & & \\
\hline Paradoxical reaction & $12(24.0 \%)$ & $32(35.2 \%)$ & .171 & .582 & .267 & 1.268 \\
\hline CSF Cells & 159.340 & 206.242 & .152 & & -17.474 & 111.277 \\
\hline CSF protein & 256.772 & 252.019 & .953 & & -163.99 & 154.488 \\
\hline CSF sugar & 35.112 & 35.422 & .925 & & -6.153 & 6.773 \\
\hline
\end{tabular}

CSF cerebrospinal fluid, HIV human immunodeficiency virus, $B I$ Barthel index, TBM tuberculous meningitis Note: Statistically significant $P$-values are depicted in italics

inflammatory changes that could produce clinical deterioration and imaging changes [19]. Another significant predictor of paradoxical reaction was a shorter duration of illness. Possibly, a large mycobacterial load and subsequent release of mycobacterial antigen following antituberculosis treatment resulted in a higher frequency of paradoxical reactions among patients who developed tuberculous meningitis comparatively rapidly.

A substantial proportion of our HIV-infected patients (11 out of 13 patients) developed paradoxical reactions. Many studies in the past have noted that many patients develop tuberculous meningitis associated IRIS. Manifestations of central nervous system tuberculosis IRIS include meningitis, cerebral parenchymal tuberculoma, brain abscesses, spinal cord complications like myeloradiculopathy, and spinal epidural abscesses [20-22]. In a prospective study, $47 \%(16 / 34)$ of tuberculous meningitis patients developed tuberculous meningitis-IRIS. At inclusion, tuberculous meningitis-IRIS patients had a higher cerebrospinal fluid neutrophil counts compared with non-tuberculous meningitis-IRIS patients [20]. There is a consensus that antiretroviral therapy should be started early (around 2 weeks) in HIV/tuberculosis co-infected patients. In HIV and tuberculous meningitis co-infected patients, because of a potential risk of tuberculous meningitis associated IRIS, antiretroviral therapy may be delayed; however, there is no consensus on this point [23].

We observed that the development of paradoxical reactions did not adversely affect the outcome of tuberculous meningitis. Several studies in the past had 


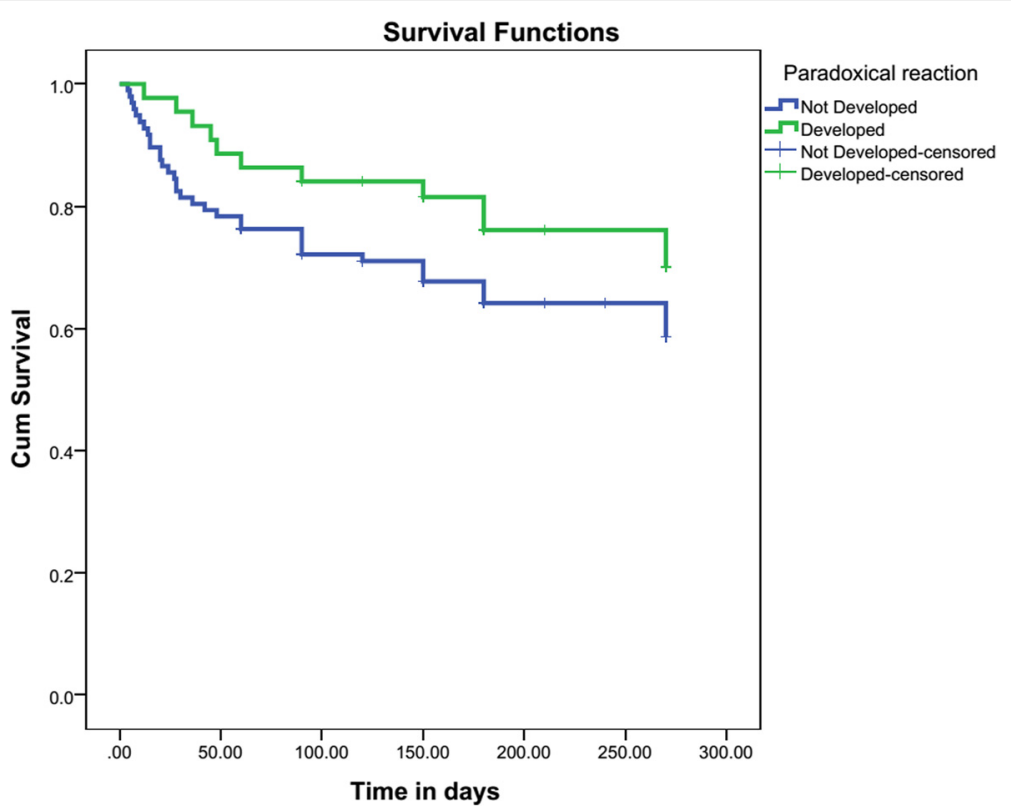

Fig. 3 Kaplan Meyer survival analysis showed no significant difference in the cumulative survival of patients with or without paradoxical reaction (Log rank test: $X^{2}(1)=2.198, P=0.138$ )

similar observations. Clinical, laboratory, radiological, and outcome data of 14 cases of paradoxical tuberculoma in tuberculous meningitis patients (out of 22 patients who had intracranial tuberculoma) were compared with 41 tuberculous meningitis patients without tuberculomas. The analysis suggested that there was no statistical difference between two groups regarding age, stage of tuberculous meningitis, duration between disease onset and treatment initiation, cerebrospinal fluid protein levels, and in long-term disabilities [24]. Many manifestations of paradoxical reactions like optochiasmatic and spinal arachnoiditis, and a large cerebral tuberculoma are serious conditions associated with severe disabilities, and a potential for death [25]. These conditions warrant urgent treatment with immunomodulatory drugs. High doses of corticosteroids are currently the most preferred treatment. Many other immunomodulatory drugs like, tissue necrosis factor- $\alpha$ antagonists, thalidomide, and interferon $-\gamma$ have also been used, though sparingly [3].

There were certain limitations of our study. It is difficult to pin-point exactly the timing of onset of a paradoxical reaction clinically. Besides this, the differential diagnosis of a paradoxical reaction may also pose a challenge. A wrong diagnosis, possibility of treatment failure, multidrug-resistance, atypical mycobacterial infection, drug toxicity, or clinical deterioration due to some unrelated cause should always be co-considered. One of our patients with apparent paradoxical reaction later turned out to have multidrug-resistant tuberculosis.

\section{Conclusion}

Paradoxical reaction occurs in approximately onethird of patients with tuberculous meningitis. Female gender, concomitant HIV infection, and a shorter duration of illness are significant predictors of such reactions. Duration of illness, alteration in consciousness, stage-III of tuberculous meningitis, and hydrocephalus, predict a poor prognosis in patients with tuberculous meningitis; paradoxical reactions, however, do not seem to affect the outcome adversely.

\section{Additional file}

Additional file 1: Table S1. Clinicoradiological, biochemical and outcome details of patients with paradoxical reaction in tuberculous meningitis. (DOCX $30 \mathrm{~kb}$ )

\section{Abbreviations}

AIDS, acquired immune deficiency syndrome; B, barthel index; HIV, human immunodeficiency virus; IRIS, immune reconstitution inflammatory syndrome; $\mathrm{MRI}$, magnetic resonance imaging

\section{Acknowledgement}

None.

\section{Funding}

Funding was not obtained for this study.

Availability of data and materials

All the data supporting your findings is contained within the manuscript.

\section{Authors' contributions}

AKS: concept of study, execution of study and data analysis and writing the manuscript. HSM: concept of study, execution of study and data analysis and writing the manuscript. RKG: concept of study, execution of study and data analysis and writing the manuscript. AJ: responsible for microbiological 
studies and manuscript writing. NK: concept of study, execution of study and data analysis and writing the manuscript. NK: responsible for conduct and assessment of Neuroimaging in the study. RV: patient evaluation and manuscript writing. PKS: patient evaluation and manuscript writing. All authors have read and approve of the final version of the manuscript.

\section{Competing interest}

On behalf of all authors, the corresponding author states that there is no conflict of interest.

\section{Consent for publish}

Not applicable.

\section{Ethics and consent to participate}

Written informed consent was obtained from the patient from each patient or his/her legal guardian. The study was approved by the Institutional Ethics Committee, King George's Medical University, U.P., India (Reference Code: 64th ECM II-B/P19).

\section{Author details}

'Department of Neurology, King George Medical University, Uttar Pradesh, Lucknow PIN-226003, India. 'Department of Microbiology, King George Medical University, Uttar Pradesh, Lucknow, India. ${ }^{3}$ Department of Radiodiagnosis, King George Medical University, Uttar Pradesh, Lucknow, India.

Received: 6 February 2016 Accepted: 7 June 2016

Published online: 21 June 2016

\section{References}

1. Afghani B, Lieberman JM. Paradoxical enlargement or development of intracranial tuberculomas during therapy: case report and review. Clin Infect Dis. 1994;19:1092-9.

2. Nicolls DJ, King M, Holland D, Bala J, del Rio C. Intracranial tuberculomas developing while on therapy for pulmonary tuberculosis. Lancet Infect Dis. 2005;5:795-801.

3. Garg RK, Malhotra HS, Kumar N. Paradoxical reaction in HIV negative tuberculous meningitis. J Neurol Sci. 2014;340:26-36.

4. Garcia-Monco JC, Ferreira E, Gomez-Beldarrain M. The therapeutic paradox in the diagnosis of tuberculous meningitis. Neurology. 2005;65:1991-2.

5. Teoh R, O'Mahony G, Yeung VT. Polymorphonuclear pleocytosis in the cerebrospinal fluid during chemotherapy for tuberculous meningitis. J Neurol. 1986;233:237-41.

6. Kim SH, Kim YS. Immunologic paradox in the diagnosis of tuberculous meningitis. Clin Vaccine Immunol. 2009;16:1847-9.

7. Meintjes G, Lawn SD, Scano F, Maartens G, French MA, Worodria W, Elliott $J H$, Murdoch D, Wilkinson RJ, Seyler C, John L, van der Loeff MS, Reiss P, Lynen L, Janoff EN, Gilks C, Colebunders R. International Network for the Study of HIV-associated IRIS. Tuberculosis-associated immune reconstitution inflammatory syndrome: case definitions for use in resource-limited settings. Lancet Infect Dis. 2008;8:516-23.

8. Marais S, Meintjes G, Pepper DJ, Dodd LE, Schutz C, Ismail Z, Wilkinson KA, Wilkinson RJ. Frequency, severity, and prediction of tuberculous meningitis immune reconstitution inflammatory syndrome. Clin Infect Dis. 2013;56:450-60.

9. Marais S, Thwaites G, Schoeman JF, et al. Tuberculous meningitis: a uniform case definition for use in clinical research. Lancet Infect Dis. 2010;10:803-12.

10. Council BMR. Streptomycin treatment of tuberculous meningitis. BMJ. 1948; 1:582-97.

11. Hawkey CR, Yap T, Pereira J, Moore DA, Davidson RN, Pasvol G, Kon OM, Wall RA, Wilkinson RJ. Characterization and management of paradoxical upgrading reactions in HIV-uninfected patients with lymph node tuberculosis. Clin Infect Dis. 2005;40:1368-71.

12. World Health Organization. Treatment of tuberculosis: guidelines. WHO/ HTM/TB/2009.420. 4th ed. World Health Organization; 2012 [http:// whqlibdoc.who.int/ publications/2010/9789241547833_eng.pdf; 2010; accessed on 9 January.2016]

13. Thwaites GE, Nguyen DB, Nguyen HD, et al. Dexamethasone for the treatment of tuberculous meningitis in adolescents and adults. N Engl J Med. 2004;351:1741-51.

14. National AIDS Control Organization. National Guidelines on Second-line and Alternative First-line ART For Adults and Adolescents. Department of Health
\& Family Welfare Government of India New Delhi, India. Downloaded from http://www.naco.gov.in/upload/Policies\%20\&\%20Guidelines/Antiretroviral\% 20Therapy\%20Guidelines\%20for\%20HIV-Infected\%20Adults\%20and\%20 Adolescents.pdf Assessed on January 7, 2016.

15. Cheng VC, Yam WC, Woo PC, Lau SK, Hung IF, Wong SP, et al. Risk factors for development of paradoxical response during antituberculosis therapy in HIV-negative patients. Eur J Clin Microbiol Infect Dis. 2003;22:597-602.

16. Sütlas PN, Unal A, Forta $H$, Senol S, Kirbas D. Tuberculous meningitis in adults: review of 61 cases. Infection. 2003:31:387-91.

17. Nhamoyebonde S, Leslie A. Biological differences between the sexes and susceptibility to tuberculosis. J Infect Dis. 2014;209 Suppl 3:S100-6.

18. Neyrolles O, Quintana-Murci L. Sexual inequality in tuberculosis. PLoS Med. 2009;6, e1000199.

19. Bell LC, Breen R, Miller RF, Noursadeghi M, Lipman M. Paradoxical reactions and immune reconstitution inflammatory syndrome in tuberculosis. Int J Infect Dis. 2015;32:39-45.

20. Crump JA, Tyrer MJ, Lloyd-Owen SJ, Han LY, Lipman MC, Johnson MA. Miliary tuberculosis with paradoxical expansion of intracranial tuberculomas complicating human immunodeficiency virus infection in a patient receiving highly active antiretroviral therapy. Clin Infect Dis. 1998;26:1008-9.

21. Pepper DJ, Marais S, Maartens G, Rebe K, Morroni C, Rangaka MX, Oni T, Wilkinson RJ, Meintjes G. Neurologic manifestations of paradoxical tuberculosis-associated immune reconstitution inflammatory syndrome: a case series. Clin Infect Dis. 2009:48(11):e96-107.

22. Marais S, Scholtz P, Pepper DJ, Meintjes G, Wilkinson RJ, Candy S. Neuroradiological features of the tuberculosis-associated immune reconstitution inflammatory syndrome. Int J Tuberc Lung Dis. 2010;14:188-96.

23. Lawn SD, Wood R. Poor prognosis of HIV-associated tuberculous meningitis regardless of the timing of antiretroviral therapy. Clin Infect Dis. 2011:52(11):1384-7.

24. Unal A, Sutlas PN. Clinical and radiological features of symptomatic central nervous system tuberculomas. Eur J Neurol. 2005:12:797-804.

25. Sinha MK, Garg RK, Anuradha HK, Agarwal A, Singh MK, Verma R, et al. Vision impairment in tuberculous meningitis: predictors and prognosis. J Neurol Sci. 2010;290:27-32.

\section{Submit your next manuscript to BioMed Central and we will help you at every step:}

- We accept pre-submission inquiries

- Our selector tool helps you to find the most relevant journal

- We provide round the clock customer support

- Convenient online submission

- Thorough peer review

- Inclusion in PubMed and all major indexing services

- Maximum visibility for your research

Submit your manuscript at www biomedcentral com/submit
Ciomed Central 